\title{
Estimativa teórica da geração de biogás do futuro aterro sanitário de Ji-Paraná - RO
}

\author{
Theoretical estimate of landfill gas generation of the future landfill in Ji-Paraná - RO \\ Helder Sumeck Necker', Ana Lúcia Denardin da Rosa² \\ ${ }^{2}$ Departamento de Engenharia- Ambiental Universidade Federal de Rondônia - UNIR- RO
}

\section{Resumo}

A destinação dos resíduos sólidos urbanos ainda é um problema na maior parte do Brasil, notadamente nas regiões Norte e Nordeste. No município de Ji-Paraná - RO, a atual destinação dos resíduos não acontece de maneira adequada, sendo que o projeto de construção de um aterro sanitário para o município já existe e deve acontecer em breve. Além da mais adequada forma de destinação final dos resíduos sólidos urbanos, os aterros sanitários podem ser uma forma de se obter energia, devido à sua grande geração de biogás, que apresenta em sua composição o metano, um gás com elevado potencial energético. Portanto, o trabalho buscou estimar a geração de biogás no aterro sanitário que será construído em Ji-Paraná, com base em 2 metodologias: Método do Inventário e Método de Projeto. Foram encontrados valores que chegam a 5,8 milhões de $\mathrm{m}^{3}$ de biogás gerado por ano e o potencial de geração de biogás dos resíduos foi de aproximadamente $216 \mathrm{~m}^{3}$ de biogás por tonelada de resíduo. Nos anos iniciais de funcionamento, o potencial energético do aterro foi estimado em $144 \mathrm{MW}$ por mês, sendo que, depois de cerca de uma década de funcionamento, a energia gerada chegaria a $432 \mathrm{MW} / \mathrm{mês}$ e poderia abastecer cerca de 2.800 residências.

Palavras-chaves: Potencial energético, resíduos sólidos, metano

\begin{abstract}
The final destination of the urban solid waste stills a problem in the bigger part of Brazil, principally, in regions north and northeast. In the city of Ji-Paraná - RO, the current final destination of the solid waste don't happens in a correct way, and that the project of construction of a landfill for the city already exists and should starts soon. Beyond the most appropriate way of urban solid waste final destination, the landfills can be a way of obtain energy, because of the great generation of landfill gas, that presents in their composition methane, one gas with a huge energetic potential. Therefore this work, search to estimate the generation of landfill gas in the landfill that will be built in Ji-Paraná, based on two methods: Inventory Method and Project Method. The values founded gets around 5.8 million $\mathrm{m}^{3}$ of landfill gas in a year and the potential generation of the solid waste founded were nearly of $216 \mathrm{~m}^{3}$ of landfill gas for ton of solid waste. In the firsts years of operation, the energetic potential of the landfill was estimated in $144 \mathrm{MW}$ per month and after near then a decade of operation, the energetic potential could reach $432 \mathrm{MW}$ per month e could provide electricity for about of 2.800 houses.
\end{abstract}

Keywords: Energetic potential, solid waste, methane 


\section{INTRODUÇÃO}

As questões referentes à geração e destinação final do lixo são temas recorrentes em todo o mundo, Donha (2002), cita que na década de 50 a geração mundial de lixo era de $0,5 \mathrm{~kg} / \mathrm{hab}$.dia e em 2000 esse número chegou a $2,0 \mathrm{~kg} /$ hab.dia nos países desenvolvidos, sendo que no Brasil, há uma produção média de $0,7 \mathrm{~kg} / \mathrm{hab}$.dia, e nos grandes centros urbanos do país este número pode chegar a 1,0 kg/hab.dia.

Um panorama apresentado pela ABRELPE (2010) mostrou que $29,5 \%$ dos municípios brasileiros ainda dispõem seus resíduos sólidos urbanos (RSU) em lixões, 31,6\% em aterros controlados e $38,9 \%$ em aterros sanitários. Portanto na maioria dos municípios os resíduos não têm a correta destinação final, sendo que as regiões menos desenvolvidas, como o Norte e o Nordeste apresentam as piores condições quanto à destinação final dos resíduos, ainda segundo a ABRELPE (2010) somente $18,9 \%$ dos municípios da região Norte destina seus RSU em aterros sanitários e no Nordeste o número é de $24,5 \%$.

De acordo com o IPCC (1996) os aterros são responsáveis por cerca de 5 a $20 \%$ do metano que é liberado por fontes que tem em sua origem a atividade humana. O gás metano tem um potencial de aquecimento aproximadamente 20 vezes maior que o do dióxido de carbono, sendo responsável por $25 \%$ do aquecimento global (USEPA, 2007). Nesse sentido, ENSINAS (2003) diz que, nos aterros sanitários devem ser realizados projetos que visam à recuperação do biogás do aterro para geração de eletricidade, bem como por motivos de segurança, saúde pública e ambiental.

Segundo Zanette (2009), o processo de digestão anaeróbia, o qual ocorre nos aterros sanitários, vem sendo utilizado em diversas aplicações que demonstraram a sua capacidade de tratamento de resíduos sólidos e efluentes líquidos constituídos em sua maior parte de matéria orgânica. O biogás é uma mistura gasosa produzida a partir da decomposição anaeróbia de materiais orgânicos, composta primariamente de metano e dióxido de carbono, com pequenas quantidades de ácido sulfídrico e amônia (ZANETTE, 2009).

O poder calorífero do biogás varia de 5.000 a $7.000 \mathrm{kcal} / \mathrm{m}^{3}$ em função da percentagem que o metano participa de sua composição, sendo que esse valor pode chegar a $12.000 \mathrm{kcal} / \mathrm{m}^{3}$ se o dióxido de carbono e outros contaminantes forem eliminados da mistura (SILVA, 2009). Segundo PERSSON et al. (2006) o percentual de metano no biogás de aterros sanitários varia de 35 a $65 \%$, enquanto o de dióxido de carbono de 15 a $50 \%$.

Países que não possuem recursos hídricos como o Brasil, investem mais em fontes alternativas de energia, como a solar, eólica e de biomassa. De acordo com Willumsen (2001), os países que mais exploram o potencial energético dos aterros sanitários são Estados Unidos, com 325 projetos de recuperação e a Alemanha, com 150, sendo que o Brasil apresenta apenas 6 projetos.

O trabalho realizado teve por objetivo, estimar teoricamente a quantidade de biogás que será gerada no aterro sanitário que se encontra em fase de projeto e será construído no município de Ji-Paraná - RO, desde que, o mesmo seja construído e manejado de forma adequada.

\section{METODOLOGIA}

O estudo foi desenvolvido considerando o aterro sanitário que será construído no município de Ji-Paraná que conforme dados do IBGE (2010), é o segundo município do Estado de Rondônia em população e economia, localizado na região central do estado. Possui uma população de 116.610 habitantes, sendo que destes 104.858 residem na zona urbana. O aterro sanitário será localizado ao lado do atual lixão, distante cerca de $10 \mathrm{~km}$ da cidade, com uma área de 45 ha. A precipitação anual média em Ji-Paraná é de $1740 \mathrm{~mm} /$ ano (ANA, 2013), sendo que, a região apresenta duas estações bem definidas, uma chuvosa nos meses setembro a maio, e outra seca, de junho a agosto.

Foram realizadas estimativas através de métodos empíricos já consagrados na literatura, sendo eles o Método do Inventário e o Método de Projeto.

\section{I Equação de inventário desenvolvida pelo IPCC (1996)}

Esse método que foi apresentado pelo IPCC em 1996 é um método simples para estimativa de emissão de metano em aterros sanitários, Britto (2006) explica que esse método envolve a estimativa da quantidade de carbono orgânico degradável que está presente no resíduo, assim, a quantidade de metano que pode ser gerada por determinada quantidade de resíduo é calculada. O método utiliza dados estatísticos da população e características dos resíduos sólidos urbanos. seguinte:
A equação utilizada pelo método é a 
$\mathrm{CH}_{4}=\left(\right.$ PopUrb $\times$ Taxa RSU $\times$ RSDf $\left.\times \mathrm{L}_{0}-\mathrm{R}\right) \mathrm{x}$ (1 - OX)

Sendo que:

$\mathrm{CH}_{4}$ - quantidade de gás metano emitido em toneladas de $\mathrm{CH} 4$ /ano;

PopUrb - número de habitantes residentes na área urbana;

Taxa RSU - resíduos sólidos urbanos gerados, dado em toneladas de RSU/habitante $\mathrm{x}$ ano;

RSDf - fração dos resíduos que é coletada e depositada no aterro sanitário;

$\mathrm{L}_{0}$ - potencial de geração de metano dos resíduos em toneladas de $\mathrm{CH} 4 /$ toneladas de resíduo;

$\mathrm{R}$ - metano que é captado e aproveitado em toneladas de $\mathrm{CH} 4 /$ ano;

OX - fator de oxidação do metano na superfície do aterro sanitário.

O fator de oxidação do metano (OX) representa a quantidade de metano que é oxidada, seja na camada de resíduos ou na superfície do aterro (GRACINO, 2010). De acordo com o IPCC (1996), esse fator ainda vem sendo estudado e enquanto novos dados não são apresentados utiliza-se o valor de OX como sendo zero, porém Miller et al. (2009), utilizaram em seu trabalho o fator de oxidação como sendo 0,1 para aterros bem manejados.

O potencial de geração de metano dos resíduos $\left(\mathrm{L}_{0}\right)$ é um dado de muita importância, além de ser utilizado na própria metodologia desenvolvida pelo IPCC, também pode ser utilizado em outras metodologias e até mesmo em softwares desenvolvidos para estimativa de metano gerado em aterros sanitários. $\mathrm{O} \mathrm{L}_{0}$ é calculado através da seguinte fórmula:
$\mathrm{L}_{0}=\mathrm{FCM} \times \mathrm{COD} \times \mathrm{CODf} \times \mathrm{F} \times 4 / 3$

Sendo:

$\mathrm{L}_{0}$ - o potencial de geração de metano dos resíduos em toneladas de $\mathrm{CH} 4 /$ tonelada de resíduo;

FCM - fator de correção de metano;

COD - carbono orgânico degradável, dado em tonelada de C/tonelada de resíduo;

CODf - fração de COD dissociada;

$\mathrm{F}$ - fração do metano presente no biogás em volume;

(4/3) - fator de conversão do carbono em metano, dado em tonelada de $\mathrm{CH} 4 /$ tonelada de C.

O fator de correção do metano (FCM) varia de acordo com a qualidade da compactação dos resíduos, pois considera que a maneira como os resíduos são depositados influencia na geração de metano do aterro sanitário. O FCM pode ser de: 0,4 para lugares de deposição inadequados e com profundidades de lixo menores que 5 metros; de 0,8 para lugares de deposição inadequados, porém com profundidades de lixo maiores que 5 metros; e 1 para locais adequados, com deposição controlada de lixo, material de cobertura, compactação mecânica e nivelamento do terreno. $\mathrm{O}$ valor de $\mathrm{F}$, que representa a fração de metano que está presente no biogás varia, nos aterros sanitários, segundo Persson et al. (2006), o percentual de metano em sua composição fica entre 35 e $65 \%$.

Outra variável de extrema importância é a quantidade de carbono degradável presente nos resíduos (COD), que leva em conta a composição gravimétrica dos resíduos sólidos urbanos e a quantidade de carbono presente em cada componente do lixo, o que pode ter grandes variações de um local para outro.

Tabela 1. Teor de carbono orgânico degradável em cada componente dos resíduos.

\begin{tabular}{lc}
\hline Componente & $\begin{array}{c}\text { Porcentagem de COD (em } \\
\text { massa) }\end{array}$ \\
\hline A - papel e papelão & 40 \\
B - resíduos de parques e & 17 \\
jardins & \\
C - restos de alimentos & 15 \\
D - tecidos & 40 \\
E - madeira* & 30 \\
\hline
\end{tabular}

\footnotetext{
* excluindo a fração de lignina por se decompor muito lentamente.
}

Fonte: Britto (2006). 
O COD é calculado da seguinte forma:

$\mathrm{COD}=(0,4 \times \mathrm{A})+(0,17 \times \mathrm{B})+(0,15 \times \mathrm{C})+(0,4 \times \mathrm{D})+$ $(0,3 \times \mathrm{E})$

Sendo:

A - fração de papel e papelão dos resíduos;

B - fração de detritos de parques e jardins dos resíduos;

C - fração de restos de alimentos dos resíduos;

D - fração de tecidos dos resíduos;

E - fração de madeira dos resíduos.

Há ainda a fração dissociada de carbono orgânico degradável (CODf), que segundo Birgemer e Crutzen (1987) é a fração de carbono que é disponível para a decomposição bioquímica e varia em função da temperatura na zona anaeróbia do aterro sanitário. Assume-se que a temperatura na zona anaeróbia de um local de disposição de resíduos sólidos (LDRS) permanece constante por volta dos $35^{\circ} \mathrm{C}$ não obstante da temperatura ambiente (BIRGEMER E CRUTZEN, 1987). Sendo calculada pela seguinte fórmula:

$\operatorname{CODf}=0,014 \mathrm{~T}+0,28$

Não há previsão do ano em que o aterro esteja pronto e em funcionamento, portanto, adotou-se o ano de 2015 de uma maneira representativa, pois se acredita que de acordo com a situação atual, o aterro não entre em funcionamento antes desta data, sendo que, caso inicie suas operações em anos posteriores a 2015 não haverá influência significativa na geração de metano, pois o único dado que irá se alterar será o do número de habitantes, que será maior.

O método adotado para estimar o crescimento populacional do município foi o de Projeção Geométrica, que calcula o crescimento populacional em função da população existente a cada ano. A taxa anual de crescimento utilizada foi de $0,93 \%$, pois é uma média das taxas de crescimento encontradas nos censos de 2000 e 2010 . Foi considerando uma taxa de urbanização do município, com a tendência de que a população urbana cresça mais que a população rural, atualmente, a taxa de urbanização encontra-se na faixa de $88 \%$, conforme o Plano Municipal estima, e segundo o mesmo trabalho, espera-se que ela passe a 90\% em 2020 e chega aos $95 \%$ a partir de 2031 .

A metodologia desenvolvida pelo IPCC é importante, pois os valores de COD e de L0 que são encontrados através dela são utilizados também em outras metodologias.

\subsection{Método de Projeto}

Há uma metodologia desenvolvida pela Agência de Proteção Ambiental dos Estados Unidos que é recomendada para aterros sanitários que ainda não estão em funcionamento, encontrando-se em fase de projeto, a CETESB/SMA (2003) explica que esse método é dividido em duas etapas, uma enquanto o aterro ainda está em operação e outra que é após o seu fechamento, portanto existem duas equações a ser utilizadas:

Durante a vida útil do aterro:

$\mathrm{Q}=\mathrm{F} \times \mathrm{R} \times \mathrm{L} 0 \times\left(1-\mathrm{e}^{-\mathrm{kt} t}\right)$

Após o fechamento do aterro:

$\mathrm{Q}=\mathrm{F} \times \mathrm{R} \times \mathrm{L}_{0} \times\left(\mathrm{e}^{-\mathrm{kc}}-\mathrm{e}^{-\mathrm{kt}}\right)$

Sendo que:

$\mathrm{Q}$ - metano gerado em $\mathrm{m}^{3} / \mathrm{ano}$

$\mathrm{F}$ - fração de metano presente no biogás;

$\mathrm{R}$ - resíduos que serão depositados durante a vida útil do aterro em $\mathrm{kg} \mathrm{RSU/ano;}$

$\mathrm{L}_{0}$ - potencial de geração de biogás em $\mathrm{m}^{3}$ de biogás/kg resíduo;

$\mathrm{k}$ - constante de decaimento;

c - tempo decorrido em anos desde que o aterro foi fechado;

$\mathrm{t}$ - tempo decorrido em anos desde que o aterro foi aberto.

Nesse método há a utilização da constante de decaimento (k), que varia em função da disponibilidade de nutrientes, $\mathrm{pH}$, temperatura e principalmente umidade e precipitação pluviométrica da região, estes valores variam de 0,01 ano- 1 a 0,09 ano-1. Segundo o World Bank (2003), para regiões com precipitações anuais médias maiores que $1.000 \mathrm{~mm}$ e resíduos considerados de alta decomposição o valor de (k) pode ser considerado como sendo 0,09 ano-1.

\subsection{Equivalência energética do biogás}

Para a conversão de biogás em energia, é importante verificar a forma de tratamento que o biogás receberá e a fração de biogás que será recuperada e utilizada para conversão energética. De forma a verificar o potencial energético do aterro que será construído em Ji-Paraná, foi feito 
o cálculo da energia elétrica que seria gerada com a utilização de um motogerador de mesmo modelo instalado na planta de biogás do aterro Essencis - CTR Caieiras, o motogerador LANDSET, que foi objeto de estudo de Figueiredo (2007).

O motogerador LANDSET é desenvolvido pela empresa Brasmetano e segundo a fabricante é capaz de gerar energia elétrica a partir do biogás, com potência nominal de $230 \mathrm{~kW}$, sendo fabricados no Brasil e fornecidos prontos para instalação, possuindo vida útil de 40 a 80 mil horas, possuindo uma eficiência elétrica de $28 \%$.

É possível estimar a vazão de biogás necessária para a alimentação do motor para gerar uma potencia de $200 \mathrm{~kW}$ através da Eq. 7.

Pot $=(\mathrm{Q} \times \mathrm{PCI} \times \mathrm{n}) / 860$

Sendo que:

Pot - potência gerada;

$\mathrm{Q}$ - vazão de biogás $\mathrm{em} \mathrm{m}^{3} / \mathrm{h}$;

PCI - poder calorífero do biogás;

$\mathrm{n}$ - eficiência elétrica do motor;

860 - conversão kcal para kW

\section{RESULTADOS E DISCUSSÃO}

\section{I Equação de Inventário Desenvolvida Pelo IPCC (1996)}

a) cálculo do carbono degradável (COD)

Para o cálculo do carbono degradável dos resíduos foi utilizado o estudo de Santos (2011), que realizou a análise gravimétrica dos resíduos sólidos urbanos de Ji-Paraná - RO, os resíduos quantificados por ele foram divididos em matéria orgânica, papel/papelão, plástico filme, plásticos, metais, vidro e outros, conforme tabela 2.

Desses materiais os papeis e papelões se enquadram segundo a tabela 1 como o componente A e a matéria orgânica foi considerada como o componente C. Os outros componentes não tiverem representação, devido ao estudo realizado por Santos (2011) não dividir os resíduos entre os componentes específicos para a o método de estimativa apresentado pelo IPCC, portanto, através da Eq. 3 o COD encontrado foi o seguinte.

$\mathrm{COD}=(0,4 \times 0,159)+(0,15 \times 0,616)$

$\mathrm{COD}=0,1554 \mathrm{t}$ de $\mathrm{C} / \mathrm{t}$ de resíduo

\section{b) cálculo da fração do carbono}

degradável dissociada (CODf)

Para o cálculo da fração do carbono degradável dissociada, que segundo Birgemer e Crutzen (1987) é a fração de carbono que é disponível para a decomposição bioquímica e varia em função da temperatura na zona anaeróbia do aterro sanitário, foi considerado está temperatura como sendo $35^{\circ} \mathrm{C}$, já que ainda segundo o autor assume-se que a temperatura na zona anaeróbia de um local de disposição de resíduos sólidos permanece por volta dos $35^{\circ} \mathrm{C}$. Portanto, devido ao aterro sanitário estar apenas em fase de projeto e não ser possível a medição da temperatura na zona anaeróbia, foi considerado no cálculo essa temperatura como sendo $35^{\circ} \mathrm{C}$, substituindo os valores na Eq. 4, encontra-se o CODf.

CODf $=(0,014 \times 35)+0,28$

$\mathrm{CODf}=0,77$

c) cálculo do potencial de geração de metano dos resíduos (LO)

No cálculo do potencial de geração de metano dos resíduos, importantes considerações foram feitas. $\mathrm{O}$ fator de correção de metano (FCM) varia de acordo com a qualidade do aterramento dos resíduos, pois considera que a maneira como os resíduos são depositados influencia na geração de metano do aterro sanitário. O FCM varia de

Tabela 2. Composição gravimétrica dos resíduos sólidos urbanos em Ji-Paraná.

\begin{tabular}{lc}
\hline Componentes & Fração presente nos resíduos \\
\hline Matéria orgânica & $61,60 \%$ \\
Metais & $2,10 \%$ \\
Papel/papelão & $15,90 \%$ \\
Plástico & $4,30 \%$ \\
Vidro & $1,70 \%$ \\
Plástico-filme & $4,40 \%$ \\
Outros & $10,00 \%$ \\
\hline
\end{tabular}

Fonte: Santos (2011). 
0,4 a 1 , sendo este considerado em locais com deposição controlada de lixo, material de cobertura, compactação mecânica e nivelamento do terreno.

Para o cálculo foi considerado que o aterro que será construído será bem manejado, logo o FCM foi considerado como sendo igual a 1 . O valor de $\mathrm{F}$ considerado, foi considerado igual a $50 \%$, um valor médio entre os definidos por Persson et al. (2006). Então substitui-se os valores na Eq 2 e tem-se que:

$\mathrm{L}_{0}=1 \times 0,1554 \times 0,77 \times 0,5 \times(4 / 3)$

$\mathrm{L}_{0}=0,07977 \mathrm{t}$ de $\mathrm{CH}_{4} / \mathrm{t}$ de resíduo

$\left(\mathrm{CH}_{4}\right)$

\section{d) cálculo da quantidade metano gerado}

Para calcular as quantidades de metano geradas a cada ano foi preciso fazer uma estimativa do crescimento da população no município de Ji-Paraná, também foi considerado que o aterro comece a receber resíduos no ano de 2015 e seja fechado no ano de 2035, totalizando um tempo de vida de 20 anos, que é também o tempo estimado pela Agencia Reguladora de Serviços Públicos Delegados do Município de Ji-Paraná (AGERJI).

A taxa de geração de resíduos sólidos usada no cálculo foi a encontrada por Santos (2011), de $0,684 \mathrm{~kg} / \mathrm{hab} / \mathrm{dia}$. A estimativa da taxa de geração de resíduos por habitante é uma variável difícil de ser calculada, pois depende de vários fatores, como os hábitos que a população deverá adquirir e o crescimento econômico do município. A CETESB realizou em 1998 o Inventário Nacional de Emissões de Metano pelo Manejo de Resíduos para os anos de 1990 a 1994, usando em suas estimativas a taxa de $0,5 \mathrm{~kg} / \mathrm{hab} /$ dia para todos os anos. Portanto devido a esses fatores, optou-se por considerar o valor encontrado por Santos (2011) constante para as estimativas em Ji-Paraná.

Atualmente a taxa da população urbana atendida pela coleta pública de resíduos, segundo a empresa responsável pela coleta, é de 100\%, assim esse valor foi considerado para utilização do modelo para os próximos 20 anos. O valor de $\mathrm{R}$ é considerado como sendo zero, pois ele representa a quantidade de metano que é captada no aterro. $\mathrm{O}$ valor de oxidação do metano $(\mathrm{OX})$ foi considerado como sendo 0,1 já que Miller et al. (2009) utilizaram em seus trabalhos este valor para aterros bem manejados e também foi adotado considerando um cenário mais pessimista, ou seja, um cenário onde $10 \%$ do metano seja oxidado, se perdendo. Sendo assim, com a Eq. 1, para o ano de 2015 a quantidade de metano gerada no aterro sanitário seria de:

$$
\begin{aligned}
& \mathrm{CH}_{4}=(107.479 \times 0,250 \times 1 \times 0,07977-0) \times(1-0,1) \\
& \mathrm{CH}_{4}=2 \cdot 609.897,7 \mathrm{~m}^{3} / \text { ano }
\end{aligned}
$$

Refazendo o cálculo anterior substituindo a população urbana de 2015 pelas populações estimadas dos anos subseqüentes pode-se obter a tabela 3.

Tabela 3. Valores de emissão de metano.

Fonte: Modificado de Plano Municipal de Saneamento Básico de Ji-Paraná (2012).

\subsection{Método de Projeto}

\begin{tabular}{ccc}
\hline Ano & $\begin{array}{c}\text { População } \\
\text { estimada }\end{array}$ & $\begin{array}{c}\text { Quantidade de metano } \\
\text { gerada }\left(\mathrm{m}^{3}\right)\end{array}$ \\
\hline 2015 & 107.479 & $2.609 .897,7$ \\
2020 & 115.130 & $2.788 .680,4$ \\
2025 & 120.586 & $2.920 .835,7$ \\
2030 & 126.299 & $3.059 .216,0$ \\
2035 & 139.633 & $3.382 .192,4$ \\
\hline
\end{tabular}

Para a estimativa de metano gerado através dessa metodologia, foram utilizados os mesmos valores do Método do Inventário, para que a comparação entre os valores estimados pelas duas metodologias pudesse se realizada de melhor forma.

Os dados a serem considerados nesta metodologia foram os seguintes:

- Potencial de geração de biogás dos resíduos $\left(\mathrm{L}_{0}\right)=0,2156 \mathrm{~m}^{3}$ de biogás $/ \mathrm{kg}$ de resíduo. Foi utilizado o valor encontrado pela equação (2), e considerado para conversão o peso específico do metano como sendo $0,740 \mathrm{~kg} / \mathrm{m}^{3}$ (CEGAS, 2005). Para transformar o valor encontrado pela equação (2) para a unidade utilizada no Método de Projeto, o valor foi divido pelo peso específico do metano para que a unidade fosse o volume e depois dividida pela fração de metano considerada nas estimativas, 50\%: (0,07977 $\mathrm{kg} \mathrm{CH}_{4} / \mathrm{kg}$ de R) / $\left(0,74 \mathrm{~kg} / \mathrm{m}^{3}\right) /(0,5)=0,2156 \mathrm{~m}^{3}$ de biogás $/ \mathrm{kg}$ de $\mathrm{R}$

- Fração de metano presente no biogás (F) $=0,5$ (este valor só pode ser conhecido ao certo quando o aterro já se encontrar em funcionamento e com uma análise dos gases emitidos, como isso não é possível, foi adotado o valor médio da fração de metano no biogás segundo Persson et al. (2006) que varia de 35 a $65 \%$ )

- Constante de decaimento $(\mathrm{k})=0,09$ (foi definido com base nos valores sugeridos pelo World Bank (2003), visto que a precipitação média no município é de $1.740 \mathrm{~mm} /$ ano e considerando os 
resíduos do município como de alta decomposição);

- Quantidade média de resíduos depositados no aterro durante sua vida útil $(\mathrm{R})=31.955 .331,56$ $\mathrm{kg}$ de RSU/ano (este valor foi calculado com base no crescimento populacional geométrico assim como no método anterior e como no Plano Municipal de Saneamento Básico (2012) de Ji-Paraná e considerando que o aterro receba resíduos de 2015 a 2035, assim como para o cálculo anterior do método do inventário).

Foram realizados cálculos de geração de metano pelo aterro para os anos de 2015 até 2055 , que é onde as emissões já acontecem em uma menor quantidade.

O método prevê o uso de duas equações, uma para o período em que o aterro estará recebendo resíduos e outra para quando este já tenha sido fechado. Com os resultados encontrados foi produzido um gráfico, mostrando o comportamento do aterro e de suas emissões com o passar dos anos, podemos ver os resultados na figura 1 .

O pico de produção do aterro sanitário ocorre no último ano em que o mesmo ainda recebe resíduo, no ano de 2035 , a geração de metano nesse ano chega a $2.875 .365,6 \mathrm{~m}^{3}$.

$\mathrm{Q}_{2035}=0,5 \times 31.955,56 \times 0,2156 \times\left(1-\mathrm{e}^{-0,09 \times 20)}\right.$

$\mathrm{Q}_{2035}=2.875 .365,6 \mathrm{~m}^{3}$

Esse modelo é mais fiel ao real comportamento dos aterros, pois considera que a geração de metano vai crescendo com o tempo de maturação e com o acúmulo de resíduos no aterro sanitário e também estima a geração de metano nos anos posteriores ao fechamento do aterro, através deste modelo podemos verificar que as emissões continuam por longos períodos de tempo.

\subsection{Equivalência Energética do Biogás}

Através da Eq. 7 apresentada anteriormente, substituindo os valores na fórmula e sabendo que segundo o fabricante o motor LANDSET possui uma eficiência elétrica de $28 \%$, é possível estimar a vazão de biogás necessária para a alimentação do motor para gerar uma potencia de $200 \mathrm{~kW}$.

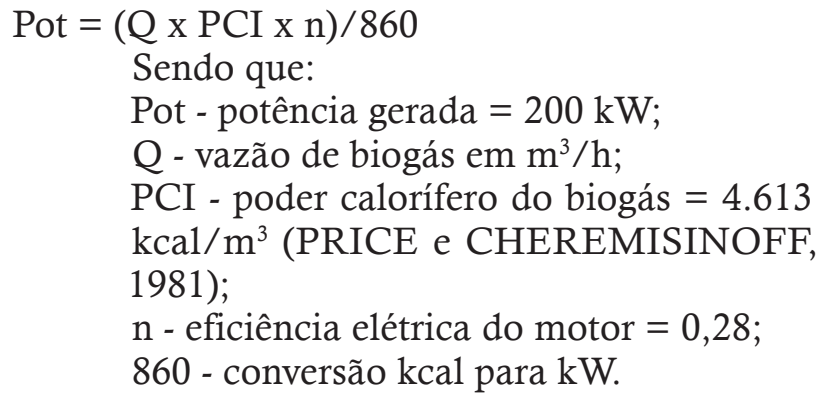

O resultado estimado foi igual a aproximadamente $135 \mathrm{~m}^{3} / \mathrm{h}$, sendo esta, portanto, a vazão necessária para abastecer o gerador com potencia de $200 \mathrm{~kW}$.

Através da vazão anual do biogás podemos estimar a potencia e energia que estará disponível no aterro sanitário que será construído em Ji-Paraná. Também há de se considerar que dificilmente é implantado um sistema que possibilite que $100 \%$ do biogás seja coletado, sendo que valores comuns da chamada eficiência de coleta do biogás chegam a 75\%, como Figueiredo (2007) considera em seu trabalho. Portanto com estas

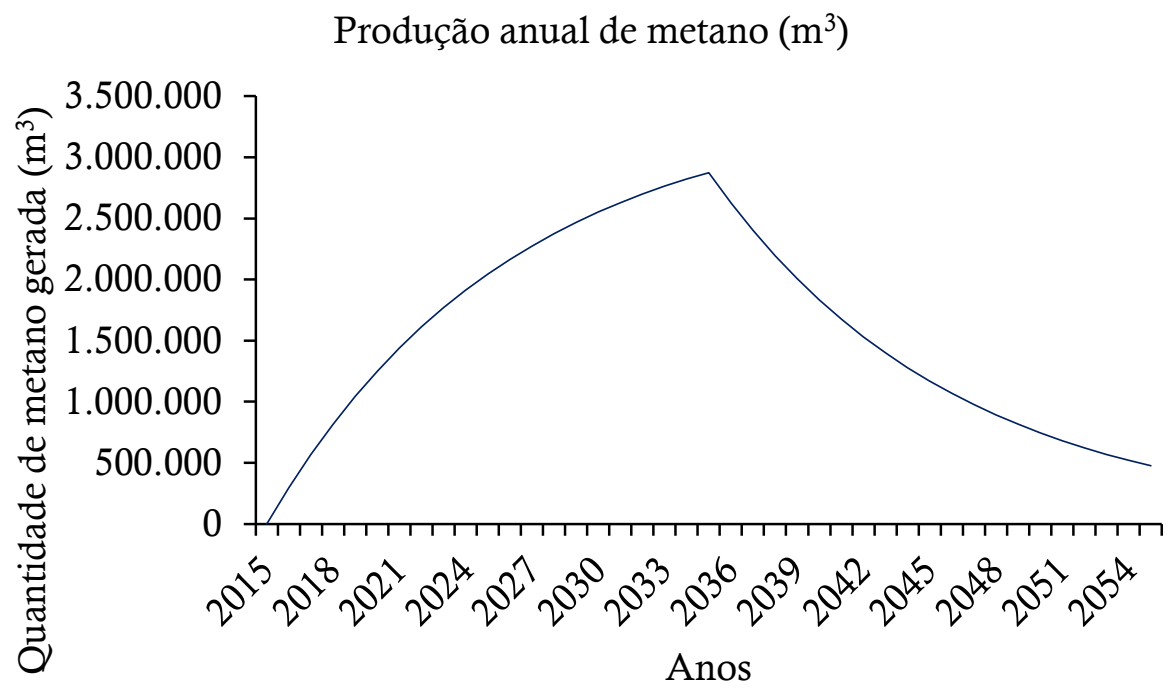

Figura 1. Gráfico com as estimativas de emissão de metano para os anos de 2015 até 2055 no aterro sanitário que será construído em Ji-Paraná. 
Tabela 4. Vazão de biogás, no aterro sanitário que será construído em Ji-Paraná - RO.

\begin{tabular}{|c|c|c|}
\hline Ano & $\begin{array}{c}\text { Vazão Biogás } \\
\left(\mathrm{m}^{3} / \mathrm{ano}\right)\end{array}$ & $\begin{array}{c}\text { Vazão Biogás } \\
\left(\mathrm{m}^{3} / \text { hora }\right) \\
(75 \%)\end{array}$ \\
\hline 2016 & $592.978,8$ & 50,8 \\
\hline 2017 & $1.134 .917,2$ & 97,2 \\
\hline 2018 & $1.630 .213,6$ & 139,6 \\
\hline 2019 & $2.082 .880,0$ & 178,3 \\
\hline 2020 & $2.496 .586,0$ & 213,7 \\
\hline 2021 & $2.874 .684,8$ & 246,1 \\
\hline 2022 & $3.220 .241,2$ & 275,7 \\
\hline 2023 & $3.536 .056,0$ & 302,7 \\
\hline 2024 & $3.824 .688,8$ & 327,5 \\
\hline 2025 & $4.088 .479,6$ & 350,0 \\
\hline 2026 & $4.329 .566,0$ & 370,7 \\
\hline 2027 & $4.549 .902,4$ & 389,5 \\
\hline 2028 & $4.751 .274,8$ & 406,8 \\
\hline 2029 & $4.935 .315,2$ & 422,5 \\
\hline 2030 & $5.103 .515,6$ & 436,9 \\
\hline 2031 & $5.257 .239,2$ & 450,1 \\
\hline 2032 & $5.397 .732,0$ & 462,1 \\
\hline 2033 & $5.526 .132,8$ & 473,1 \\
\hline 2034 & $5.643 .482,0$ & 483,2 \\
\hline 2035 & $5.750 .731,2$ & 492,4 \\
\hline 2036 & $5.255 .772,8$ & 450,0 \\
\hline 2037 & $4.803 .414,4$ & 411,3 \\
\hline 2038 & $4.389 .990,4$ & 375,9 \\
\hline 2039 & $4.012 .149,2$ & 343,5 \\
\hline 2040 & $3.666 .828,0$ & 313,9 \\
\hline 2041 & $3.351 .228,8$ & 286,9 \\
\hline 2042 & $3.062 .792,4$ & 262,2 \\
\hline 2043 & $2.799 .181,6$ & 239,7 \\
\hline 2044 & $2.558 .259,2$ & 219,0 \\
\hline 2045 & $2.338 .072,8$ & 200,2 \\
\hline 2046 & $2.136 .837,6$ & 182,9 \\
\hline 2047 & $1.952 .922,8$ & 167,2 \\
\hline 2048 & $1.784 .836,8$ & 152,8 \\
\hline 2049 & $1.631 .218,0$ & 139,7 \\
\hline 2050 & $1.490 .821,2$ & 127,6 \\
\hline 2051 & $1.362 .508,0$ & 116,7 \\
\hline 2052 & $1.245 .238,4$ & 106,6 \\
\hline 2053 & $1.1380 .62,4$ & 97,4 \\
\hline 2054 & $1.040 .110,4$ & 89,1 \\
\hline 2055 & $950.589,6$ & 81,4 \\
\hline
\end{tabular}

considerações obtemos a tabela 4 com as vazões de biogás $\left(\mathrm{m}^{3} / \mathrm{h}\right)$, considerando uma eficiência de coleta de $75 \%$, encontradas pelo Método de Projeto.

A partir do quarto ano de funcionamento do aterro (2018) já haverá vazão suficiente (139,6 $\mathrm{m} 3 / \mathrm{h}$ ) para alimentação de um motor LANDSET, sendo possível gerar $144 \mathrm{MW}$ de energia por mês, considerando que a vazão de biogás é constante o motor pode funcionar 24 horas por dia, todos os dias. Sendo assim $200 \mathrm{~kW} \times 24 \mathrm{~h}$ x 30 dias $=144$ MW.

Segundo a Empresa de Pesquisa Energética (EPE, 2011), o consumo médio de energia de uma residência foi $154 \mathrm{kWh} /$ mês no ano de 2010 no Brasil, e a energia gerada pelo aterro sanitário em 2018 foi 144 MW por mês, sendo assim possível para abastecer cerca de 930 residências por igual período de tempo. No ano de 2028 o aterro já teria vazão suficiente para abastecer 3 conjuntos geradores com potencia de $200 \mathrm{~kW}$, gerando 432 MW por mês, suficiente para abastecer cerca de 2.800 residências.

\section{CONCLUSÕES}

Através dos métodos de estimativa utilizados, percebe-se que Ji-Paraná teria uma grande geração de biogás em seu futuro aterro sanitário, chegando a gerar quase 6 milhões de $\mathrm{m}^{3}$ de biogás anualmente. O biogás gerado nos períodos de maior produção do aterro sanitário, seria suficiente para abastecer cerca de 2.800 residências.

A composição gravimétrica dos resíduos de Ji-Paraná por Santos (2011) mostrou um potencial de geração de metano destes resíduos de $108 \mathrm{~m}^{3} /$ tonelada. Esse potencial pode ser elevado caso seja realizada a reciclagem de resíduos como plásticos, vidros e metais, aumentado assim a proporção de matéria orgânica, papéis e papelões nos resíduos, já que estes são fontes de carbono, fator que influencia diretamente na geração de metano, aumentando assim a produção de metano por tonelada de resíduo.

\section{REFERÊNCIAS}

ANA. Agência Nacional de Águas. Sistema de Informações Hidrológicas, 2012. Disponivel em: <http:// www2.ana.gov.br/Paginas/servicos/informacoeshidrologicas/redehidro.aspx $>$. Acesso em: 15 Agosto 2013. 
Associação Brasileira de Empresas de Limpeza Pública e Resíduos Especiais - ABRELPE. Panorama dos Resíduos Sólidos no Brasil, 2010. Disponível em: <http://www.abrelpe.org.br/panorama_envio.cfm?ano=2010 > . Acessado em 20 ago. 2013

BIRGEMER, H. G. e CRUTZEN, P. J. The production of metano from solid waste. Journal of geophysical research, v. 92, n. D2, p 2181 - 2187. 1987.

BRITTO, M. L. C. P. S. Taxa de Emissão de Biogás e Parâmetros de Biodegradação de Resíduos Sólidos Urbanos no Aterro Metropolitano Centro. Tese de Mestrado, Salvador, Bahia, 2006.

CEGAS - Companhia de Gás do Ceará. Site: < www.cegas.com.br/gasna>. Acesso em: 10/08/2013.

DONHA, M. S. Conhecimento e Participação da Comunidade no Sistema de Gerenciamento de Resíduos Sólidos Urbanos: O Caso de Marechal Cândido Rondon - PR. Dissertação (Mestrado) - Florianópolis, 2002. 130p.

EPE - Empresa de Pesquisa Energética. Balanço Energético Nacional, 2012. Rio de Janeiro: EPE, 2012.

FIGUEIREDO, N. J. V. Utilização do Biogás de Aterro Sanitário para Geração de Energia Elétrica e Iluminação a Gás - Estudo de Caso. São Paulo, SP. 2007.

GRACINO, M. C. S. Caracterização dos Aterros Sanitários de Araçatuba e Região e o Potencial do Aterro Sanitário da Cidade de Araçatuba para Produção de Biogás. Faculdade de Tecnologia de Araçatuba. Araçatuba, São Paulo, 2010.

INÁCiO, C. T.; BETTIO, D. B.; MILlER, P. R. M. Potencial de Mitigação de Emissões de Metano via Projetos de Compostagem de Pequena Escala. Congresso Brasileiro de Resíduos Orgânicos. Vitória, Espírito Santo, 2009.

\section{INSTITUTO BRASILEIRO DE GEOGRAFIA E} ESTATÍSTICA - IBGE. Censo Demográfico 2010. Disponível em: <http://www.ibge.gov.br>. Acesso em: 30 setembro 2013 .

IPCC - Intergovernmental Panel on Climate Change, Guidelines for Greenhouse Gas inventory: reference Manual, revised - Chapter 6 - Waste, 1996.
LANDGEM (Landfill Gas Emissions Model), Version 3.01 - User's Guide, EPA - Environmental Research Group (2005) in Estudo do potencial da geração de energia renovável proveniente dos "aterros sanitários" nas regiões metropolitanos e grandes cidades do Brasil, Convenio FEALQ - Ministério do Meio Ambiente, 2004.

PERSSON, M., JÖNSSON, O., WELLINGER, A., 2006. Biogas upgrading to vehicle

fuel standards and grid injection. IEA Bioenergy, Task 37 - Energy from Biogas and Landfill Gas.

PREFEITURA DO MUNICÍPIO DE JI-PARANÁ. Plano Municipal de Saneamento Básico: Plano Setorial de Limpeza Urbana, Manejo e Gestão Integrada de Resíduos Sólidos do Município de Ji-Paraná. Relatório Final, Ji-paraná, 2012.

PRICE, E. C., CHEREMISINOFF, P. N. Biogas Production and utilization. New York,

NY: Ann Arbor Science, 1995.

SANTOS, L. R. Caracterização Física Dos Resíduos Sólidos Urbanos Do Município De Ji-Paraná - Rondônia. Trabalho de Conclusão de Curso, Ji-Paraná, Rondônia, 2011. UNIR.

SILVA, C. A. B. V. Limpeza e Purificação de Biogás. Dissertação de Mestrado. Universidade de Trás-os-Montes e Alto Douro, Portugal, 2009.

WILLUMSEN, H. C. "Energy recovery from land fi 11 gas in Denmark and

worldwide”. LG Consultant, 2001.

WORLD BANK. Handbook for the preparation of landfill gas to energy projects in Latin America and Caribbean. 1818 H Street NW, Washington, DC 20433, USA: World Bank, 2003.125p.

ZANETTE, A. L. Potencial de Aproveitamento Energético do Biogás no Brasil. Dissertação de Mestrado, Rio de Janeiro, Rio de Janeiro, 2009. 